\title{
Revenue and Knowledge Cooperation Mechanisms between Business Incubators and Venture Capitalists for Collaborative Start-Ups
}

\author{
Wenqing Wu, Qing Han \\ College of Management and Economics, Tianjin University, Tianjin, China \\ Email: wenqingw@tju.edu.cn
}

How to cite this paper: $\mathrm{Wu}, \mathrm{W} . \mathrm{Q}$. and Han, Q. (2017) Revenue and Knowledge Cooperation Mechanisms between Business Incubators and Venture Capitalists for Collaborative Start-Ups. Theoretical Economics Letters, 7, 1335-1356.

https://doi.org/10.4236/tel.2017.75091

Received: July 8, 2017

Accepted: July 30, 2017

Published: August 2, 2017

Copyright (c) 2017 by authors and Scientific Research Publishing Inc. This work is licensed under the Creative Commons Attribution International License (CC BY 4.0).

http://creativecommons.org/licenses/by/4.0/

\begin{abstract}
Business incubators and venture capital are effective instruments for supporting the development of new firms. The purpose of this paper is to explore cooperation mechanisms between business incubators and venture capitalists and find the equilibriums of the mechanisms. Also, this paper puts forward three mechanisms, revenue sharing mechanism, cost sharing mechanism and knowledge sharing mechanism, to discuss the cooperation between business incubators and venture capitalists. Meanwhile, we consider the effect of the business incubator's altruism and compare the three cooperation mechanisms with and without altruism. The results indicate that the mechanism of revenue sharing leads to the highest incubator's revenue sharing proportion. Additionally, the incubator's revenue sharing proportion decreases even though its final profit increases when considering altruism. Therefore, the nonprofit incubator can be better for cooperating with the venture capitalist than the profit incubator. Finally, financial returns can influence their cooperation.
\end{abstract}

\section{Keywords}

Business Incubator, Venture Capitalist, Revenue Sharing Mechanism, Cost Sharing Mechanism, Knowledge Sharing Mechanism

\section{Introduction}

Business incubators are institutions that cultivate small and medium-sized enterprises. They provide infrastructure, technology and related services to promote technological innovation and help the new ventures survive in their early stages [1]. Although the business incubators originated in the 1980s, the quantity and capability of incubators have constantly increasing even today [2]. Schwartz [3] compares the survival rates of 371 incubator firms after their graduation with 
the survival rates of 371 non-incubated firms. The results suggest a higher survival rate among incubated firms than among firms outside the incubators. A great deal of research shows that the incubators are significant in reducing the high failure rate for new ventures because they obtain necessary resources from the incubators [4] [5] [6] [7].

By now, there are many business incubators that serve new ventures and have incubated many new ventures successfully. However, after surveys and interviews with the managers of the new ventures, Tang et al. [8] find that the incubators are good at providing physical infrastructure and administrative support but ineffective in offering finance, strategy, or other intangible resources. Therefore, the new ventures need to seek financial help, such as venture capital. Venture capital firms provide new ventures with funds that will support the valueadded activities of the new venture [9] [10].

As mentioned above, the incubator's resource support and the venture capitalist's fund assist the new venture's development. Generally, incubators are increasingly likely to partner with venture capitalists, creating new business relationships in this area. Nevertheless, only a few scholars have explored the relationship between the incubator and the venture capitalist. To obtain more investment opportunities for new ventures and establish contact with the enterprise earlier, some venture capitalists fund the business incubators. Avnimelech et al. [11] suggest that the incubator obtains funds from the venture capitalist, which can lead to higher incubation performance. However, the relationship in which the incubator obtains financial support from the venture capitalist is not cooperation. Cumming [12] believes that the relationship between the incubator and the venture capitalist should be more reasonable. Callegati et al. [13] note that business incubators would be more successful when cooperating with the venture capitalists even though the incubator would face more challenges. Therefore, cooperation between business incubators and venture capitalists is significant to the future success of new ventures. Further studies on the cooperation mechanism between the business incubator and venture capitalist should be performed.

Moreover, most of the business incubators are non-profit organizations that aim to assist the start-ups but not obtain more profit [14]. These non-profit incubators often behave altruistically to support the development of the new ventures. Therefore, the research should consider the altruistic characteristic of business incubators, which influences the incubation performance dramatically.

In this paper, we model three cooperation mechanisms between business incubators and venture capitalists: the revenue sharing mechanism, the cost sharing mechanism and the knowledge sharing mechanism. The revenue sharing mechanism reflects the case where the venture capitalist funds the new venture and the incubator provides advice to the new venture. In this case, they share the revenue of the new venture. In contrast, under the cost sharing mechanism, the venture capitalist not only funds the new venture but also bears some of the cost. The incubator and the venture capitalist share the revenue and the cost during the incubation process. Under the knowledge sharing mechanism, the incubator 
and the venture capitalist both provide knowledge and share the revenue. Finally, we derive the solutions of different mechanisms using game theory. Moreover, we add the incubator's altruism to the mechanisms and determine those solutions. Finally, we compare the solutions of the three mechanisms mentioned above and the profits of the incubator and evaluate the effects of altruism.

The following passage is organized as follows. Section 2 reviews the relevant literature about business incubators, venture capitalists and cooperation mechanisms. In the next two sections, we establish three collaboration mechanisms between the incubator and the venture capitalist, including the revenue sharing mechanism, cost sharing mechanism and knowledge sharing mechanism, and determine the equilibrium of different mechanisms. In the fifth section, we expand the model based on the altruism of the incubator and then compare the solutions with and without the altruism factor. Finally, Section 6 presents the conclusions.

\section{Literature Review}

Since business incubators emerged in the 1990s, they have been widely known as useful institutions that provide services to the new ventures. Morant and Ribeiro [15] note that the incubators provide not only facilities but also advice on experienced monitoring skills, marketing plans and technological knowledge. Knowledge, as an important resource in the development of the firms, has been studied widely as well as in the incubators and incubating firms [16]. Rothaermel and Thursby [17] suggest that incubators, and particularly university business incubators, should enhance the knowledge flow between the incubator and the incubating firms. Cooper et al. [18] also emphasize the knowledge transfer between the incubating firms and the business incubators.

Although they receive assistance from the incubator, new ventures may fail because of insufficient funds. Thus, financial support from venture capitalists enables the new firm to survive. Venture capitalist provides funds to the new venture in the early stages to help its development [19]. Ding et al. [20] study the optimal investment decision for venture capitalists by establishing the cooperative and non-cooperative models with venture entrepreneurs. Meanwhile, the venture capitalist can provide knowledge about management to the new venture. Christian [21] proposes a model for the venture capitalist and the entrepreneur to discuss how the venture capitalist boosts better innovation. In this model, the venture capitalist not only provides funds but also advises the start-ups.

The relationships among the three parties can be described as follows: the incubator provides tangible resources, and the venture capitalist provides financial support to the new venture. The incubator and the venture capitalist both contribute to the new venture's development. At present, cooperation between the incubator and the venture capitalist is crucial to motivate the improvement of a high-tech venture. The cooperation mechanism between the incubator and the venture capitalist has received little attention in existing research. Gaspar [22] confirms that the incubator's network and the venture capitalist's funds enable 
the new venture to develop further. Avnimelech et al. [11] perform the empirical work to examine whether the interaction between the incubator and the venture capitalist is beneficial for the new venture. The results suggest that the interaction increases the incubation's success rate. Wu et al. [23] examine the efforts of the incubator, the venture capitalist, and the new venture through establishing a trilateral game model. They conclude that in the cooperation, each of them contributes their best effort. In contrast, if the three parities do not collaborate, their profit cannot achieve equilibrium.

On the other hand, cooperation between firms has become increasingly crucial during the past decade. A large number of firms cooperate with others to improve their competitiveness. Numerous studies examine this cooperation. Ge et al. [24] study the $\mathrm{R} \& \mathrm{D}$ cooperation of firms in a supply chain. The results show that firms in a supply chain both contribute to the R \& D and benefit from the cooperation. Bonte and Keilbach [25] investigate the formal and informal cooperation for innovation between firms, and they state that large firms are more likely to engage in formal cooperation, whereas the informal cooperation of $\mathrm{R} \& \mathrm{D}$ innovation is more prevalent among the small and medium-sized enterprises.

Generally, the cooperation mechanisms between firms can be identified three categories: the revenue sharing mechanism, cost sharing mechanism and knowledge sharing mechanism. The pure revenue sharing contract is often used in supply chain coordination [26]. The revenue sharing mechanism in a supply chain means that the retailer shares a part of the revenue with the manufacturer. Sang [27] establishes revenue sharing contract between the manufacture and the retailer to coordinate the supply chain. Through the revenue sharing mechanism, the expected profit of the whole supply chain can be realized. The revenue sharing mechanism can be adopted in other fields to coordinate the relationship. The cost sharing mechanism is also pervasive in the supply chain. Ghosh and Shah [28] model the cost sharing contract and analyze its influence on prices and profits in the supply chain. They assume that the two parties in the supply chain share the manufacturing setup cost and the final revenue, which can encourage the manufacturer to create and maximize the profit of the whole supply chain. Roma and Perrone [29] compare the outcome-based and the ex-ante based cost sharing mechanisms between two firms. In the cost sharing mechanisms, the two firms undertake the cost together, and the result finds the outcome-based sharing mechanism can lead to more welfare.

In addition to the revenue sharing and the cost sharing mechanisms, the knowledge sharing mechanism has also been a topic of recent study. Knowledge flow refers to knowledge transfers from one generation to the next [30]. Along with the tremendous advances of the society, the knowledge transfer theory impacts the management of firms. Knowledge flows and exchanges between individuals and organizations are increasingly significant along with the tremendous advance of society. Human factors, stakeholder roles, power relationships, knowledge sources, organizational factors and external influences should be 
considered to improve knowledge exchanges [31]. A knowledge network could be used to reflect the knowledge interaction between the incubators and the incubating firms. In addition, both specialized and diversified business incubators could reinforce the network structure [32]. Bhaskaran and Krishnan [33] argue that collaboration between firms is important given the growing sophistication of technology and the rising cost of product. They model the effort, revenue, and cost sharing mechanisms for new product development between two firms. Therefore, the three kinds of sharing mechanisms are worthy of reference to the cooperation between the incubator and venture capitalist.

However, few researchers have considered the altruism of business incubators. Incubators as a kind of non-profit organization often behave altruistically. Altruism, the opposite of selfishness, refers to helping others or engaging in a mutually beneficial arrangement. Sibly and Curnow [34] study the altruism and selfishness of individuals, and other literature examines the altruism of firms. Dur and Tichem [35] study the impact of the altruism from the firm's managers and employees on incentive contracts. Haynes et al. [36] study the impacts of greed and altruism behaviors by a manager. They find that the firm benefits from altruism. Guinot et al. [37] also note that altruism promotes firms' learning capacity. Philosophers argue that altruism is the moral duty of individuals, whereas some economists view altruism as non-market behavior within families but not within firms [38]. Actually, business incubators often engage in altruistic behaviors. Grimaldi and Grandi [39] define business innovation centers and university business incubators as non-profit institutions, whereas some private incubators are for-profit institutions. They note that the main model of the incubators is non-profit. Markman et al. [40] investigate 128 university business incubators and conclude that most incubators are non-profit. Helping the new firms and encouraging creation are the targets of the non-profit incubator. Therefore, the incubator's altruism impacts its decisions and cooperation among the three parties.

Faced with increasingly fierce competition, many enterprises pursue opportunities for cooperating with others, and they benefit from the cooperation. In summary, there are three typical cooperation mechanisms: the revenue sharing mechanism, the cost sharing mechanism and the knowledge sharing mechanism. At the same time, the service advantage of the incubator and the financial advantage of the venture capitalist are complementary. The cooperation between the incubator and the venture capitalist has been increasingly emphasized, but little research examines the cooperation mechanism between the incubator and the venture capitalist. Therefore, the cooperation mechanisms should be explored. In this paper, we adopt the three mechanisms to enhance the cooperation between the incubator and the venture capitalist. In addition, the altruism factor of the incubator has been considered in the cooperation. We analyze the consequences of these arrangements for each party to see if the results are really as beneficial as intended.

The main contributions of this paper are as follows. First, we creatively apply 
the revenue sharing mechanism and cost sharing mechanism to the cooperation between the incubator and the venture capitalist. Next, since the knowledge flow in the firms is extremely significant to the creation of new firms, our paper designs the knowledge sharing mechanism to discuss the knowledge flow from the incubator and the venture capitalist to new firms. Based on the literature mentioned above, we add the altruism of the incubator to the three mechanisms and determine the collaboration decisions. Moreover, we compare the mechanisms to identify an optimal cooperation mechanism.

\section{Model Descriptions}

In this section, we design a model to explore the collaboration mechanisms between the incubator and venture capitalist during the incubation process. We first introduce the assumptions of the model.

1) The incubation from the business incubator is successful and the new venture obtains profits.

2) The business incubator and venture capitalist are completely rational and they reach an agreement to cooperate.

3) The revenue sharing proportion of the new venture is fixed.

4) To encourage better incubation from business incubator to new ventures, the government gives financial return to the incubator after successful incubation. In this paper, we use Nash solutions to solve the bargaining problem.

The cooperation between the incubator and venture capitalist forms a bargaining problem and they cooperate to decide how to share the revenue, cost or knowledge. Nash [41] came up with a structure to solve the bargaining problem to reach the equilibrium between two cooperative persons. In this paper, we obtain Nash bargaining solutions to discuss the cooperation between the incubator and venture capitalist.

Then we design the model. We assume the original value of the new venture is $\alpha(\alpha \geq 0)$, and the value will improve after obtaining assistance from incubator and venture capitalist. The business incubator incubates the new venture and decides its quality improvement $\theta(\theta \geq 0)$. We assume $v$ is the conversion efficiency parameter, and then the increased value of the new firm would be $v \theta$. After incubation, the final value of the new venture can be described as $\alpha+v \theta$. The tax ratio of the government is $l(0<l<1)$, and the after-tax profit of the new venture is $(1-l)(\alpha+v \theta)$. The revenues are divided among the three parties according to revenue sharing parameters $x$ and $y$. We assume $x$ is the proportion of revenue shared by the incubator, and $y$ is the revenue sharing parameter of the new venture. Once the incubation succeeds, the incubator's profit is $x(1-l)(\alpha+v \theta)$, the profit of the new venture is $y(1-l)(\alpha+v \theta)$ and the venture capitalist's profit is $(1-x-y)(1-l)(\alpha+v \theta)$. In practice, the incubator can receive financial return from the government that is proportional to the tax on the new venture. We assume the proportion of the government's financial return is $R(0<R<1)$. Then, the increased revenue of the incubator is $I R(\alpha+v \theta)$. Finally, the revenues of the incubator, the venture capitalist, and the 
new firm without considering the cost are as follows.

The incubator's revenue is

$$
U_{1}=x(1-l)(\alpha+v \theta)+l R(\alpha+v \theta)
$$

The venture capitalist's revenue is

$$
U_{2}=(1-x-y)(1-l)(\alpha+v \theta)
$$

The new venture's revenue is

$$
U_{3}=y(1-l)(\alpha+v \theta)
$$

In addition, we consider the cost during the incubator's support to the firm, which is related to the level of the new firm's quality improvement. We assume that the upfront cost is $I \theta^{2}$ (Let $I$ be the cost parameter). In addition to the upfront costs, the incubator will also dedicate resources to the new firm during the incubation process. Other cost which is proportional to the quality improvement $\theta$ and the incubation time $t$ can be represented as $c \theta t$ ( $c$ is a fixed parameter). The time of the incubation is inversely proportional to the incubation speed $\lambda$. To simplify the function, we use $\theta / \lambda$ to replace $t$ and the final cost is $I \theta^{2}+c \theta^{2} / \lambda$. We use $\pi$ represent the profits of the three bodies in the model. Furthermore, the superscripts, RS, CS, KS represent the revenue sharing mechanism, cost sharing mechanism and knowledge sharing mechanism respectively. Then, the profit functions of the incubator, venture capitalist, and the new venture are as follows.

The incubator's profit function is

$$
\pi_{1}^{R S}=x(1-l)(\alpha+v \theta)+l R(\alpha+v \theta)-I \theta^{2}-c \theta^{2} / \lambda
$$

The venture capitalist's profit function is

$$
\pi_{2}^{R S}=(1-l)(1-x-y)(\alpha+v \theta)
$$

The new venture's profit function is

$$
\pi_{3}^{R S}=y(1-l)(\alpha+v \theta)
$$

\section{Solutions}

In this section, we determine the solutions and compare the differences between the sharing mechanisms. According to the functions of different sharing mechanisms, we obtain the solutions for an optimal sharing agreement using the Nash bargaining game. In Nash bargaining problem, the incubator and the venture capitalist make decisions cooperatively. The decision-making order is that the incubator chooses the sharing mechanism and then the incubator and the venture capitalist decide the revenue sharing parameters based on the Nash bargaining game. Finally, they determine the optimal quality improvement for the new firm.

\subsection{Revenue Sharing Mechanism}

Under the revenue sharing condition, we assume that the venture capitalist 
provides financial support and the incubator provides elements such as equipment, laboratories, and research facilities. During the incubation process, the incubator bears all of the cost. Therefore, the profits under the revenue sharing mechanism are the same as (4) (5) (6). Based on the above functions, we obtain the equilibrium $x^{R S}$ of the revenue sharing mechanism, which is presented in Proposition 1.

Proposition 1. There exists a solution to the revenue sharing mechanism which is

$$
x^{R S} \in\left(\frac{1-y}{2}-\frac{1}{2} \frac{l R}{1-l}, \frac{3(1-y)}{4}-\frac{l R}{4(1-l)}\right)
$$

All the proofs can be seen in the Appendix.

Proposition 1 shows that the profit sharing ratio of the incubator under the revenue sharing mechanism is more than $\frac{1-y}{2}-\frac{1}{2} \frac{l R}{1-l}$, but less than $\frac{3(1-y)}{4}-\frac{l R}{4(1-l)}$. In this case, the incubator and the venture capitalist cooperate to support the new venture's development. When the revenue sharing parameter of the incubator is $x^{R S}$, the venture capitalist's revenue sharing ratio will be $\left(1-x^{R S}-y\right) \in\left(\frac{(1-y)}{4}+\frac{l R}{4(1-l)}, \frac{1-y}{2}+\frac{1}{2} \frac{l R}{1-l}\right)$.

\subsection{Cost Sharing Mechanism}

While supporting the firm, the incubator bears the cost, such as the use of equipment, laboratories, and research facilities. If the venture capitalist agrees to bear part of the cost, the incubator's financial pressure is reduced, and the incubator can provide better service to the success of new ventures. In the cost sharing mechanism, which differs from the revenue sharing mechanism, the venture capitalist assumes part of the costs in the process of cooperation with the incubator to encourage better service by the incubator. We assume that the proportion of the incubation cost borne by the incubator is $k$, and the venture capitalist bears the remainder of the cost. Consequently, the cost of the incubator is $k(c+I \lambda) \theta^{2} / \lambda$. The cost that the venture capitalist bears is $(1-k)(c+I \lambda) \theta^{2} / \lambda$.

According to (4)-(6), the profit functions under the cost sharing mechanism are as follows.

The incubator's profit function is

$$
\pi_{1}^{C S}=[(1-l) x+l R](\alpha+v \theta)-k * \frac{c+I \lambda}{\lambda} \theta^{2}
$$

The venture capitalist's profit function is

$$
\pi_{2}^{C S}=(1-x-y)(1-l)(\alpha+v \theta)-(1-k) \frac{c+I \lambda}{\lambda} \theta^{2}
$$

The new venture's profit function is 


$$
\pi_{3}^{C S}=y(1-l)(\alpha+v \theta)
$$

After modeling the profit functions of the three parties, we obtain the equilibrium under the cost sharing mechanism. Unlike the revenue sharing mechanism, the incubator and venture capitalist must decide the proportion of the cost, not only the revenue sharing parameter. Let $x^{C S}$ and $k^{C S}$ represent the revenue and the cost sharing ratio of the incubator, respectively. The equilibrium of the cost sharing mechanism is listed in Proposition 2.

Proposition 2. 1) Under cost sharing, the equilibrium solution of the Nash problem can be

$$
x^{C S}=\frac{1-y}{2}-\frac{l R}{2(1-l)}, \quad k^{C S}=1 / 2 .
$$

2) $x^{C S}<1-x^{C S}-y^{C S}$. The profit sharing ratio of the incubator is less than the venture capitalist's sharing ratio.

From Proposition 2, we know that the incubator's revenue proportion in the cost sharing mechanism is $x^{C S}=\frac{1}{2}-\frac{l R}{2(1-l)}-\frac{y(1+b)}{2}$ and $x^{C S}$ is less than $\left(1-x^{C S}-y\right)$. The results suggest that the profit proportion of the incubator is smaller than the venture capitalist's when they adopt the cost sharing mechanism. In other words, the venture capitalist will require more profit when bearing the cost. The solution $k^{C S}=1 / 2$ means they share the same cost equally. When the incubator adopts the cost sharing mechanism, the best result for coordination is bearing half of the cost.

\subsection{Knowledge Sharing Mechanism}

The business incubator's assistance, including laboratories, research facilities, networks and management services to the new firm, is significant to the new firm's innovation ability and effective management. Nevertheless, as mentioned above, the venture capitalist is more professional with regard to the market information, business plan and other knowledge. Therefore, in the knowledge sharing mechanism, we consider the knowledge flow between the incubator, venture capitalist and the new firm. In this section, we model that the venture capitalist provides not only finance but also knowledge about markets and management. In this case, the business incubator and the venture capitalist both provide the new firm with knowledge to better develop the new firm. Moreover, when the incubator and the venture capitalist share the knowledge, they must coordinate and distribute the work reasonably. Meanwhile, coordinating with each other incurs additional costs.

Let $\theta$ present the level of the quality improvement of the firm. Let $\theta_{1}$ be the quality improvement from the incubator's knowledge input, and $\theta_{2}$ be the quality improvement from the venture capitalist's knowledge input. In addition, $\theta=\theta_{1}+\theta_{2}$, and the increasing cost is $C=m\left(\theta_{1}^{2}+\theta_{2}^{2}\right)$. Finally, the profit functions of the incubator, venture capitalist and the new venture under the knowledge sharing mechanism are as follows. 


$$
\begin{gathered}
\pi_{1}^{K S}=[(1-l) x+l R](\alpha+v \theta)-\frac{c+I \lambda}{\lambda} \theta_{2}^{2}-m\left(\theta_{1}^{2}+\theta_{2}^{2}\right) \\
\pi_{2}^{K S}=(1-x-y)(1-l)(\alpha+v \theta)-\frac{c+I \lambda}{\lambda} \theta_{1}^{2}-m\left(\theta_{1}^{2}+\theta_{2}^{2}\right) \\
\pi_{3}^{K S}=y(1-l)(\alpha+v \theta)
\end{gathered}
$$

Based on the profit functions (13)-(15), the optimal knowledge sharing arrangement has been summarized in Proposition 3. Let $\theta_{1}^{K S}$ and $\theta_{2}^{K S}$ be the optimal knowledge sharing levels of the incubator and the venture capitalist, respectively.

\section{Proposition 3.}

1) The best levels of the knowledge sharing levels are

$$
\theta_{1}^{K S}=\frac{v \lambda[x(1-l)+l R]}{2(c+I \lambda+m \lambda)}, \quad \theta_{2}^{K S}=\frac{v \lambda(1-x-y)(1-l)}{2(c+I \lambda+m \lambda)} .
$$

2) The optimal revenue proportion of the incubator is

$$
x^{K S}=\frac{1}{2}-\frac{l R}{2(1-l)}-\frac{y(1+b)}{2} .
$$

3) $x^{K S}<1-x^{K S}-y$.The revenue sharing ratio of the incubator is less than the venture capitalist's sharing ratio.

Proposition 3 suggests that under the knowledge sharing mechanism, the incubator and the venture capitalist both provide knowledge to the firm to improve the value. The knowledge sharing of the incubator is $\theta_{1}^{K S}=\frac{v \lambda[x(1-l)+l R]}{2(c+I \lambda+m \lambda)}$, and the knowledge sharing of the venture capitalist is $\theta_{2}^{K S}=\frac{v \lambda(1-x-y)(1-l)}{2(c+I \lambda+m \lambda)}$. In this condition, the equilibrium is $\frac{1}{2}-\frac{l R}{2(1-l)}-\frac{y(1+b)}{2}$, which is the same as the equilibrium in the cost sharing mechanism. Similarly, the revenue proportion of the incubator is less than the proportion of the venture. As a consequence, in the knowledge sharing mechanism, the incubator reduces its profit proportion to encourage the venture capitalist to provide knowledge.

\section{The Equilibrium Based on Incubator's Altruism}

Altruism is defined as a kind of behavior that benefits others based on social morality. Altruists consider not only their profit but also others' profits. In this section, we add altruism into the incubator's decision during the study. Then, the revenue function changes when the business incubator, the venture capitalist and the new firm share the revenue. Based on altruism, the three sharing mechanisms discussed above would change as follows. (The superscripts, RSA, CSA, KSA represent the revenue sharing mechanism, cost sharing mechanism and knowledge sharing mechanism respectively when considering the incubator's altruism.) 


\subsection{Revenue Sharing Mechanism Based on Altruism}

When the business incubator, the venture capitalist and the new firm share the revenue, we model the profit proportion of the incubator as $x$, the new firm as $y$, and the venture capitalist as $1-x-y$. In this section, we add the altruism factor of the incubator into the cooperation mechanisms. Let $b$ measure the degree of the business incubator's altruism. The profit of the incubator increases when the incubation succeeds. Finally, the profit functions of the incubator, venture capitalist and the new venture under the revenue sharing mechanism based on altruism are as follows.

The incubator's profit function is

$$
\pi_{1}^{R S A}=(x+b y)(1-l)(\alpha+v \theta)+l R(\alpha+v \theta)-I \theta^{2}-c \theta^{2} / \lambda
$$

The venture capitalist's profit function is

$$
\pi_{2}^{R S A}=(1-x-y)(1-l)(\alpha+v \theta)
$$

The new firm's profit function is

$$
\pi_{3}^{R S A}=y(1-l)(\alpha+v \theta)
$$

After determining the profit functions of the three parties, we can derive the solution of the Nash bargaining problem.

Proposition 4. There is a solution to the Nash bargaining problem under the revenue sharing mechanism based on altruism:

$$
x^{R S A} \in\left(\frac{1}{2}-\frac{l R}{2(1-l)}-\frac{(1+b) y}{2}, \frac{3}{4}-\frac{l R}{4(1-l)}-\frac{3 y+b y}{4}\right) .
$$

The parameter $x^{R S A}$ is the optimal revenue sharing ratio of the incubator under the revenue sharing mechanism. Under this mechanism, the incubator and the venture capitalist both bargain for more profit. From the solution, we know that the profit proportion of the incubator will be more than

$\frac{1}{2}-\frac{l R}{2(1-l)}-\frac{(1+b) y}{2}$ but less than $\frac{3}{4}-\frac{l R}{4(1-l)}-\frac{3 y+b y}{4}$. The degree of altruism also affects the equilibrium. When the degree of altruism is higher, the range of the optimal sharing ratio is larger.

\subsection{Cost Sharing Mechanism Based on Altruism}

In the same way, we model the cost sharing mechanism based on the incubator's altruism. We assume the cost sharing proportion of the incubator is $k$, so then the cost the incubator bears is $k(c+I \lambda) \theta^{2} / \lambda$ and the cost the venture capitalist bears is $(1-k)(c+I \lambda) \theta^{2} / \lambda$. The profit functions of the incubator, the venture capitalist and the new venture under the knowledge sharing mechanism based on the altruism are as follows.

The incubator's profit function is

$$
\pi_{1}^{C S A}=[(1-l)(x+b y)+l R](\alpha+v \theta)-k * \frac{c+I \lambda}{\lambda} \theta^{2}
$$

The venture capitalist's profit function is 


$$
\pi_{2}^{C S A}=(1-x-y)(1-l)(\alpha+v \theta)-(1-k) \frac{C+I \lambda}{\lambda} \theta^{2}
$$

The new firm's profit function is

$$
\pi_{3}^{C S A}=y(1-l)(\alpha+v \theta)
$$

Similarly, we obtain the solutions of the cost sharing mechanism, which are listed as follows.

Proposition 5. 1) The revenue sharing ratio is $x^{C S A}=\frac{1}{2}-\frac{l R}{2(1-l)}-\frac{y(1+b)}{2}$ under the cost sharing mechanism based on altruism, and the cost sharing ratio is $k^{C S A}=1 / 2$.

2) $x^{C S A}<1-x^{C S A}-y$.

When we consider the incubator's altruism, the incubator's profit will increase after the new firm's success. On the other hand, the profit proportion of the incubator is less than that of the venture capitalist, which means the incubator will decrease the proportion of revenue in order to realize cooperation. The cost proportion $k$ is $1 / 2$, which suggests that the incubator and the venture capitalist bear the same cost. The equilibrium suggests that in the cost sharing mechanism, the incubator will reduce its profit proportion when it wants the venture capitalist to bear the cost. After bargaining for themselves, the incubator and the venture capitalist each bear half of the cost. Moreover, the profit proportion of the incubator decreases according to the degree of the altruism. When the degree of the altruism is high, the incubator will require a low profit sharing proportion, which corresponds to the definition of altruism. When the degree of the altruism decreases, the incubator requires more profit in order to support the new venture.

\subsection{Knowledge Sharing Mechanism Based on Altruism}

Based on altruism, the profit functions change under the knowledge sharing mechanism. Let $\pi^{K S A}$ be the profit under the knowledge sharing mechanism. $\theta_{1}, \theta_{2}$ are the quality improvements of the new venture because of knowledge sharing by the incubator and the venture capitalist. The profit functions of the three parties based on altruism are as follows.

$$
\begin{gathered}
\pi_{1}^{K S A}=[(1-l)(x+b y)+l R](\alpha+v \theta)-\frac{c+I \lambda}{\lambda} \theta_{1}^{2}-m\left(\theta_{1}^{2}+\theta_{2}^{2}\right) \\
\pi_{2}^{K S A}=(1-x-y)(1-l)(\alpha+v \theta)-\frac{c+I \lambda}{\lambda} \theta_{2}^{2}-m\left(\theta_{1}^{2}+\theta_{2}^{2}\right) \\
\pi_{3}^{K S A}=y(1-l)(\alpha+v \theta)
\end{gathered}
$$

In the knowledge sharing mechanism, the incubator and the venture capitalist both share knowledge with the new venture. We obtain the solution to the Nash bargaining problem.

Proposition 6. The quality improvement from the incubator's knowledge sharing is $\theta_{1}^{K S A}=\frac{[(x+b y)(1-l)+l R] v \lambda}{2(c+I \lambda+m \lambda)}$, and the quality improvement from 
the venture capitalist's knowledge sharing is $\theta_{2}^{K S A}=\frac{(1-x-y)(1-l) v \lambda}{2(c+I \lambda+m \lambda)}$. The equilibrium is $x^{K S A}=\frac{1}{2}-\frac{l R}{2(1-l)}-\frac{y(1+b)}{2}$.

In Proposition 6, we derive the solution as $x^{K S A}=\frac{1}{2}-\frac{l R}{2(1-l)}-\frac{y(1+b)}{2}$ which is the same as the solution of the cost sharing mechanism. Therefore, the profit percentages of the incubator of the cost sharing mechanism and the knowledge sharing mechanism are the same.

\subsection{Comparison of the Different Mechanisms}

We have obtained the Nash solutions both with and without altruism, and now we compare the solutions in the following tables. Table 1 lists the optimal revenue sharing ratio of the incubator under the three mechanisms without and with altruism. Table 2 represents the profit to the incubator under the three mechanisms.

Table 1. The solutions of the sharing mechanisms.

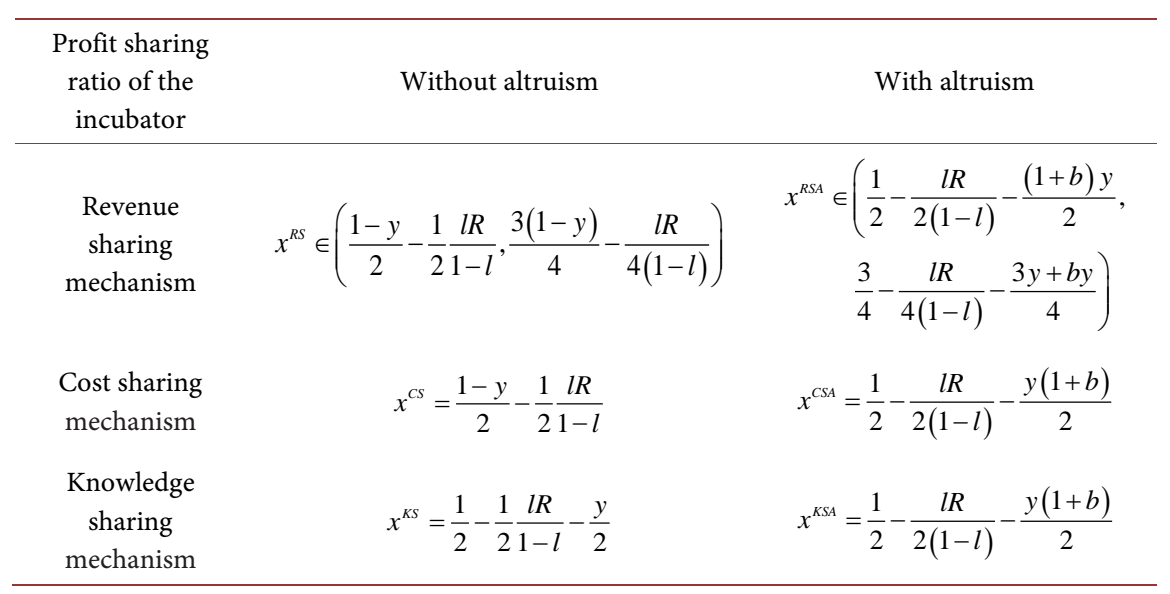

Table 2. The profit of the incubator in different mechanisms.

\begin{tabular}{|c|c|c|}
\hline $\begin{array}{l}\text { Profit of } \\
\text { the incubator }\end{array}$ & Without altruism & With altruism \\
\hline $\begin{array}{l}\text { Revenue } \\
\text { sharing } \\
\text { mechanism }\end{array}$ & $\begin{aligned} \pi^{R S}= & \alpha\left[l R+x^{R S}(1-l)\right] \\
& +\frac{v^{2} \lambda\left[l R+x^{R S}(1-l)\right]^{2}}{4(c+I \lambda)}\end{aligned}$ & $\begin{aligned} \pi^{R S A}= & \alpha\left[l R+\left(x^{R S A}+b y\right)(1-l)\right] \\
& +\frac{v^{2} \lambda\left[l R+\left(x^{R S A}+b y\right)(1-l)\right]^{2}}{4(c+I \lambda)}\end{aligned}$ \\
\hline $\begin{array}{l}\text { Cost sharing } \\
\text { mechanism }\end{array}$ & $\begin{aligned} \pi^{C S}= & \alpha * \frac{1-l+l R-y(1-l)}{2} \\
& +\frac{v^{2} \lambda[(1-l)(1-y)+l R]^{2}}{8(c+I \lambda)}\end{aligned}$ & $\begin{aligned} \pi^{C S A}= & \alpha * \frac{1-l+l R-y(1-b)(1-l)}{2} \\
& +\frac{v^{2} \lambda[1-l+l R-y(1-b)(1-l)]^{2}}{8(c+I \lambda)}\end{aligned}$ \\
\hline $\begin{array}{l}\text { Knowledge } \\
\text { sharing } \\
\text { mechanism }\end{array}$ & $\begin{aligned} \pi^{K S}= & \alpha * \frac{(1-l)(1-y)+l R}{2} \\
& +\frac{v^{2} \lambda[(1-l)(1-y)+l R]^{2}}{16(c+I \lambda+m \lambda)^{2}} \\
& *[3(c+I \lambda)+2 m \lambda]\end{aligned}$ & $\begin{aligned} \pi^{K S A}= & \alpha * \frac{1-l+l R-y(1-l)(1-b)}{2} \\
& +\frac{v^{2} \lambda[1-l+l R-y(1-l)(1-b)]^{2}}{16(c+I \lambda+m \lambda)^{2}} \\
& *[3(c+I \lambda)+2 m \lambda]\end{aligned}$ \\
\hline
\end{tabular}


We can reach some conclusions from Table 1 and Table 2 about sharing by the business incubator and venture capitalist in different conditions.

Proposition 7. $x^{R S}>x^{C S}=x^{K S}, x^{R S A}>x^{C S A}=x^{K S A}$. The revenue sharing proportion of the incubator in the revenue sharing mechanism is greater than that of the other two sharing mechanisms with and without the incubator's altruism.

Proposition 7 shows that if the business incubator provides assistance and undertakes all of the cost, which means that the venture capitalist funds the new firm only, the incubator will require more revenue sharing in proportion to the collaboration. If the incubator looks for the venture capitalist to bear part of the cost or provide knowledge together, it will decrease its revenue proportion for better collaboration. On the other hand, the venture capitalist requires more profit because it undertakes cost or provides knowledge. Moreover, the optimal profit proportion of the incubator under cost sharing is the same as that of knowledge sharing.

Proposition 8. For the profit proportion of the incubator, $x^{C S}>x^{C S A}$ and $x^{K S}>x^{K S A}$. For the final profits of the incubator, $\pi^{C S}<\pi^{C S A}$ and $\pi^{K S}<\pi^{K S A}$.

Proposition 8 shows that the revenue proportion of the incubator will decrease when considering altruism in the cost sharing and knowledge sharing mechanisms. Because of altruism, the incubator will decrease its profit proportion to help the new venture. On the other hand, according to the equation, the incubator's profits increase when adding the altruism factor. The altruism of the incubator will reduce its revenue sharing ratio, but the final profit will increase when the new firm succeeds.

Proposition 9. The incubator's revenue sharing proportion $x$ decreases as the government tax increases. In addition, $\mathrm{x}$ is decreasing in the proportion of financial return $R$.

Proposition 9 suggests that when the tax ratio increases, the revenue proportion of the incubator decreases. That indicates the incubator focuses on providing the new venture with better service, not on obtaining more profit than the tax increase. At the same time, the higher financial return will encourage the incubator to require a lower revenue sharing ratio.

\section{Conclusions}

In this paper, we discuss the collaboration mechanisms between the incubator and the venture capitalist both with and without the altruism. First, we introduce three sharing mechanisms: the revenue sharing mechanism, the cost sharing mechanism and the knowledge sharing mechanism. We then establish the profit functions of the business incubator, the venture capitalist and the new venture in different sharing mechanisms. We obtain the solutions according to the Nash bargaining game. By comparing the solutions, we analyze the cooperation mechanisms.

The main results of our research are as follows. First, the incubator will reduce its profit proportion when the venture capitalist can undertake a part of the cost 
or provide some knowledge to the new venture in the revenue sharing or the knowledge sharing mechanisms. Second, the profit proportion of the incubator is less than the proportion of the venture in the cost sharing mechanism and the knowledge sharing mechanism. Moreover, the final profit of the incubator will increase when considering altruism, even though the incubator's revenue sharing proportion will decrease. For example, when the venture capitalist provides knowledge to the new firm, the venture capitalist requires more profit. Therefore, the incubator will reduce its profit proportion and increase the venture capitalist's proportion. The incubator's profit will increase in combination with altruism. Finally, the incubator's revenue sharing proportion decreases in response to the increase of government tax and financial return.

We study three cooperation mechanisms between the incubator and venture capitalist, and several results are significant to the cooperation in practice. However, there are several limitations in this paper. We assume that the revenue sharing proportion of the new venture is fixed, but in fact, we need to consider the behavior of the new venture. Therefore, in the future research, we can explore the decisions of the three parties in the model. Furthermore, empirical study may be needed to support the model.

This research has just begun, and more explorations are needed. For example, the incubator's effort may influence the incubation process, and the effort factor should also be considered.

\section{Funding}

The paper is supported by National Social Science Foundation of China (17BGL025).

\section{References}

[1] Salvador, E. (2011) Are Science Parks and Incubators Good "Brand Names" for Spin-Offs? The Case Study of Turin. Journal of Technology Transfer, 36, 203-232. https://doi.org/10.1007/s10961-010-9152-0

[2] Mian, S., Lamine, W. and Fayoll, A. (2016) Technology Business Incubation: An Overview of the State of Knowledge. Technovation, 50, 1-12. https://doi.org/10.1016/j.technovation.2016.02.005

[3] Schwartz, M. (2013) A Control Group Study of Incubators' Impact to Promote Firm Survival. Journal of Technology Transfer, 38, 302-331.

https://doi.org/10.1007/s10961-012-9254-y

[4] Colombo, M.G. and Delmastro, M. (2002) How Effective Are Technology Incubators? Evidence from Italy. Research Policy, 31, 1103-1122. https://doi.org/10.1016/S0048-7333(01)00178-0

[5] Somsuk, N., Wonglimpiyarat, J. and Laosirihongthong, T. (2012) Technology Business Incubators and Industrial Development: Resource-Based View. Industrial Management \& Data Systems, 112, 245-267. https://doi.org/10.1108/02635571211204281

[6] Mas-Verdú, F., Ribeiro-Soriano, D. and Roig-Tierno, N. (2015) Firm Survival: The Role of Incubators and Business Characteristics. Journal of Business Research, 68, 793-796. https://doi.org/10.1016/j.jbusres.2014.11.030 
[7] Albort-Morant, G. and Oghazi, P. (2016) How Useful Are Incubators for New Entrepreneurs. Journal of Business Research, 69, 2125-2129. https://doi.org/10.1016/j.jbusres.2015.12.019

[8] Tang, M.F., Lee, J., Liu, K. and Lu, Y. (2014) Assessing Government-Supported Technology-Based Business Incubators: Evidence from China. International Journal of Technology Management, 65, 24-48. http://dx.doi.org/10.1504/IJTM.2014.060956

[9] Sapienza, H.J. and Gupta, A.K. (1994) Impact of Agency Risks and Task Uncertainty on Venture Capital. Academy of Management Journal, 37, 1618-1632. http://dx.doi.org/10.2307/256802

[10] Croce, A., Marti, J. and Murtinu, S. (2013) The Impact of Venture Capital on the Productivity Growth of European Entrepreneurial Firms: 'Screening' or 'Value added' Effect? Journal of Business Venturing, 28, 489-510.

https://doi.org/10.1016/j.jbusvent.2012.06.001

[11] Avnimelech, G., Schwartz, D. and Bar-El, R. (2007) Entrepreneurial High-Tech Cluster Development: Israel's Experience with Venture Capital and Technological Incubators. European Planning Studies, 15, 1181-1198.

http://dx.doi.org/10.1080/09654310701529078

[12] Cumming, D.J. (2012) Venture Capital: Investment Strategies, Structures, and Policies. Wiley, New York, 111-129.

[13] Callegati, E., Grandi, S. and Napier, G. (2005) Business Incubation and Venture Capital: An International Survey on Synergies and Challenges. Proceedings of 2005 INSME Annual Meeting, Barcelona, 13-15 April 2005.

[14] Klavans, R. and Boyack, K.W. (2014) Mapping Altruism. Journal of Informetrics, 8, 431-447. https://doi.org/10.1016/j.joi.2014.02.002

[15] Albort-Morant, G. and Ribeiro-Soriano, D. (2015) A Bibliometric Analysis of International Impact of Business Incubators. Journal of Business Research, 69, 1775 1779. https://doi.org/10.1016/j.jbusres.2015.10.054

[16] Mian, S.A. (1996) Assessing Value Added Contributions of University Technology Business Incubators to Tenant Firms. Research Policy, 25, 325-335. https://doi.org/10.1016/0048-7333(95)00828-4

[17] Rothaermel, F.T. and Thursby, M. (2005) University-Incubator Firm Knowledge Flows: Assessing Their Impact on Incubator Firm Performance. Research Policy, 34, 305-320. https://doi.org/10.1016/j.respol.2004.11.006

[18] Cooper, C.E., Hamel, S.A. and Connaughton, S.L. (2012) Motivations and Obstacles to Networking in a University Business Incubator. Journal of Technology Transfer, 37, 433-453. http://dx.doi.org/10.1007/s10961-010-9189-0

[19] Wang, K., Ding, C., Chen, J. and Li, A. (2016) Venture Investment Incentive Mechanisms and Simulation with Venture Entrepreneurs Having Multistage Efforts Based on Fairness Preference Theory. Discrete Dynamics in Nature and Society, 2016, Article ID: 5862576. http://dx.doi.org/10.1155/2016/5862576

[20] Ding, C., Chen, J., Liu, X. and Zheng, J. (2015) Multistage Effort and the Equity Structure of Venture Investment Based on Reciprocity Motivation. Discrete Dynamics in Nature and Society, 2015, Article ID: 689362. http://dx.doi.org/10.1155/2015/689362

[21] Christian, K. (2002) Venture Capital Backed Growth. Royal Economic Society Conference, 9, 239-261. http://dx.doi.org/10.1023/B:JOEG.0000031428.35711.fc

[22] Gaspar, F.C. (2009) The Stimulation of Entrepreneurship through Venture Capital and Business Incubation. International Journal of Entrepreneurship and Innovation Management, 9, 306-415. https://doi.org/10.1504/IJEIM.2009.024587 
[23] Wu, W.Q., Xie, F. and Zhao, L.M. (2011) Cooperation among Business Incubator, Venture Capital and Entrepreneur from the Principal-Agent's Perspective. Proceedings of IEEE International Conference on Industrial Engineering \& Engineering Management, Changchun, 3-5 September 2011, 2036-2040.

http://dx.doi.org/10.1109/ICIEEM.2011.6035569

[24] Ge, Z., Hu, Q. and Xia, Y. (2014) Firms' R\&D Cooperation Behavior in a Supply Chain. Production \& Operations Management, 23, 599-609. http://dx.doi.org/10.1111/poms.12037

[25] Bonte, W. and Keilbach, M. (2005) Concubinage or Marriage? Informal and Formal Cooperations for Innovation. International Journal of Industrial Organization, 23, 279-302. https://doi.org/10.1016/j.ijindorg.2005.01.007

[26] Cachon, G.P. and Lariviere, M. (2005) Supply Chain Coordination with Revenue Sharing Contracts: Strengths and Limitations. Management Science, 51, 30-44. https://doi.org/10.1287/mnsc.1040.0215

[27] Sang, S.J. (2016) Revenue Sharing Contract in a Multi-Echelon Supply Chain with Fuzzy Demand and Asymmetric Information. International Journal of Computational Intelligence Systems, 9, 1028-1040. http://dx.doi.org/10.1080/18756891.2016.1256569

[28] Ghosh, D. and Shan, J. (2015) Supply Chain Analysis under Green Sensitive Consumer Demand and Cost Sharing Contract. International Journal of Production Economics, 164, 319-329. https://doi.org/10.1016/j.ijpe.2014.11.005

[29] Roma, P. and Perrone, G. (2016) Cooperation among Competitors: A Comparison of Cost-Sharing, Mechanisms. International Journal of Production Economics, 180, 172-182. https://doi.org/10.1016/j.ijpe.2016.08.002

[30] Babnik, K. and Sirca, N.T. (2014) Knowledge Creation, Transfer and Retention: The Case of Intergenerational Cooperation. International Journal of Innovation \& Learning, 15, 349-364. https://doi.org/10.1504/IJIL.2014.062472

[31] Miller, K., Moffett, S., McAdam, R. and Brennan, M. (2013) Enhancing Multiple Stakeholder's Knowledge Transfer to Aid University Technology Commercialization. Lappeenranta University of Technology Press, Lappeenranta, 1-16.

[32] Zhang, H.H., Wu, W.Q. and Zhao, L.M. (2016) A Study of Knowledge Supernetworks and Network Robustness in Different Business Incubator. Physica A, 447, 545-560. https://doi.org/10.1016/j.physa.2015.12.051

[33] Bhaskaran, S.R. and Krishnan, V. (2009) Effort, Revenue, and Cost Sharing Mechanisms for Collaborative New Product Development. Management Science, 55, 1152-1169. https://doi.org/10.1287/mnsc.1090.1010

[34] Sibly, R.M. and Curnow, R.N. (2011) Selfishness and Altruism Can Coexist When Help Is Subject to Diminishing Returns. Heredity, 107, 167-173. https://doi.org/10.1038/hdy.2011.2

[35] Dur, R. and Tichem, J. (2015) Altruism and Relational Incentives in the Workplace. Journal of Economics \& Management Strategy, .24, 485-500. https://doi.org/10.1111/jems.12099

[36] Haynes, K.T., Josefy, M. and Hitt, M.A. (2015) Tipping Point: Managers' Self-Interest, Greed, and Altruism. Journal of Leadership \& Organizational Studies, 22, 265-279. https://doi.org/10.1177/1548051815585171

[37] Guinot, J., Chiva, R. and Mallen, F. (2015) The Effects of Altruism and Relationship Conflict on Organizational Learning. International Journal of Conflict Management, 26, 85-112. https://doi.org/10.1108/IJCMA-12-2013-0100 
[38] Wilson, D.S. (2016) Does Altruism Exist? Culture, Genes, and the Welfare of Others. The Independent Review, 20, 460-466.

[39] Grimaldi, R. and Grandi, A. (2005) Business Incubators and New Venture Creation: An Assessment of Incubating Models. Technovation, 25, 111-121. https://doi.org/10.1016/S0166-4972(03)00076-2

[40] Markman, G.D., Phan, P.H., Balkin, D.B. and Gianodis, P.T. (2005) Entrepreneurship and University-Based Technology Transfer. Journal of Business Venturing, 20, 241-263. https://doi.org/10.1016/j.jbusvent.2003.12.003

[41] Nash, J.F. (1950) The Bargaining Problem. Econometrica, 18, 155-162. https://doi.org/10.2307/1907266 


\section{Appendix: Proofs of Propositions}

Proof of Proposition 1. We have obtained Equations (4)-(6). To maximize the profit of the incubator, the first-order condition is 0 . That is $\mathrm{d} \pi_{1}^{R S} / \mathrm{d} \theta=0$, which means $l R v+(1-l) v x-2 I \theta-2 c \theta / \lambda=0$. We calculate the optimal incubate level of the incubator as follows:

$$
\theta^{R S}=\frac{v \lambda[l R+(1-l) x]}{2(c+I \lambda)}
$$

Then, we try to determine the solution to the Nash bargaining problem. According to economic game theory, the optimal profit percentage of the incubator would be the solution to the problem

$$
\max _{0 \leq x \leq 1} \pi^{R S}=\pi_{1} \pi_{2}
$$

Substitute $\theta^{R S}$ into $\pi$ and we derive

$$
\begin{aligned}
\pi^{R S}=\pi_{1} \pi_{2}= & \frac{2(1-l)(1-x-y) \alpha(c+I \lambda)+v^{2} \lambda(1-l)(1-x-y)[x(1-l)+l R]}{2(c+I \lambda)} \\
& * \frac{4 \alpha(c+I \lambda)[l R+(1-l) x]+v^{2} \lambda[l R+(1-l) x]^{2}}{4(c+I \lambda)}
\end{aligned}
$$

The first-order condition of (9) is

$$
\begin{aligned}
\mathrm{d} \pi^{R S} / \mathrm{d} x= & \frac{(1-l)}{8(c+I \lambda)^{2}}\left\{8 \alpha^{2}(c+I \lambda)^{2}[(1-l)(1-x-y)-[(1-l) x+l R]]\right. \\
& +6 \alpha(c+I \lambda) v^{2} \lambda[l R+x(1-l)][(1-l)(2-3 x-2 y)-l R] \\
& \left.+\left(v^{2} \lambda\right)^{2}[x(1-l)+l R]^{2}[(1-l)(3-4 x-3 y)-l R]\right\}
\end{aligned}
$$

When $0 \leq x \leq 1$, we know that

$$
\begin{aligned}
& (1-l)(1-x-y)-[(1-l) x+l R] \\
& <(1-l)(2-3 x-2 y)-l R<(1-l)(3-4 x-3 y)-l R
\end{aligned}
$$

When $0<x<\frac{1-y}{2}-\frac{l R}{2(1-l)}<\frac{1}{2},(1-l)(1-x)-[(1-l) x+l R]>0$, we know that $\mathrm{d} \pi^{R S} / \mathrm{d} x>0$.

When $1>x>\frac{3(1-y)}{4}-\frac{l R}{4(1-l)},(1-l)(3-4 x-3 y)-l R<0$, we know that $\mathrm{d} \pi^{R S} / \mathrm{d} x<0$.

In addition, $\mathrm{d} \pi^{R S} / \mathrm{d} x$ is continuous. Therefore, when $\frac{1-y}{2}-\frac{1}{2} \frac{l R}{1-l}<x<\frac{3(1-y)}{4}-\frac{l R}{4(1-l)}<\frac{3}{4}$, there is $x^{R S}$ that makes $\mathrm{d} \pi^{R S} / \mathrm{d} x=0$. We obtain a conclusion that there is a solution to the Nash bargaining problem, which is $\frac{1-y}{2}-\frac{1}{2} \frac{l R}{1-l}<x^{R S}<\frac{3(1-y)}{4}-\frac{l R}{4(1-l)}$. Proposition 1 is proven.

Proof of Proposition 2. According to the profit functions, the best level of the firm improvement is $\theta^{C S}=\frac{[x(1-l)+l R] v \lambda}{2 k(c+I \lambda)}$ when $\mathrm{d} \pi_{1}^{C S} / \mathrm{d} \theta=0$. Adding 


$$
\begin{aligned}
& \begin{aligned}
& \theta^{C S}= \frac{[x(1-l)+l R] v \lambda}{2 k(c+I \lambda)} \text { to } \pi=\pi_{1} \pi_{2}, \text { we derive } \\
& \pi^{C S}=\left\{4 k^{2}(c+I \lambda) \alpha(1-x-y)(1-l)+v^{2} \lambda[x(1-l)+l R]\right. \\
&\times[2 k(1-l)(1-x-y)-(1-k)[x(1-l)+l R]]\} \\
& \times\left\{4 k(c+I \lambda) \alpha[x(1-l)+l R]+v^{2} \lambda[x(1-l)+l R]^{2}\right\} /\left[16 k^{3}(c+I \lambda)^{2}\right] \\
& \text { When } \quad \partial \pi^{C S} / \partial x=0, \partial \pi^{C S} / \partial k=0, \\
& 16 k^{3}(c+I \lambda)^{2} \alpha^{2}[(1-l)(1-x-y)-[x(1-l)+l R]] \\
&+4 k(c+I \lambda) \alpha v^{2} \lambda[x(1-l)+l R] * 3[2 k(1-x-y)(1-l)-[x(1-l)+l R]] \\
&+\left(v^{2} \lambda\right)^{2}[x(1-l)+l R]^{2}[6 k(1-x-y)(1-l)-2[x(1-l)+l R](2-k)]=0
\end{aligned}
\end{aligned}
$$

When $x^{C S}=\frac{1-y}{2}-\frac{1}{2} \frac{l R}{1-l}$, and $k^{C S}=1 / 2$, the first-order conditions are 0. And $1-x-y=1-\frac{1-y}{2}+\frac{l R}{2(1-l)}-y=\frac{1-y}{2}+\frac{l R}{2(1-l)}>x$. Proposition 2 is proven.

Proof of Proposition 3. To maximize the profit, we make the first-order condition of (10) and (12) is 0 . In addition, the optimal levels of support knowledge are

$$
\begin{gathered}
\theta_{1}^{K S}=\frac{v \lambda[x(1-l)+l R]}{2(c+I \lambda+m \lambda)}, \\
\theta_{2}^{K S}=\frac{v \lambda(1-x-y)(1-l)}{2(c+I \lambda+m \lambda)}, \\
\theta^{K S}=\theta_{1}^{K S}+\theta_{2}^{K S}=\frac{[(1-l)(1-y)+l R] v r \lambda}{2(c+I \lambda+m \lambda)}
\end{gathered}
$$

At the same time, the profit of the incubator and the venture capitalist can be obtained.

$$
\begin{aligned}
& \pi_{1}^{K S}= \frac{4 \alpha[x(1-l)+l R](c+I \lambda+m \lambda)^{2}}{4(c+I \lambda+m \lambda)^{2}} \\
&+\frac{v^{2} \lambda(c+I \lambda+m \lambda)[x(1-l)+l R][(1-l)(2-2 y-x)+l R]}{4(c+I \lambda+m \lambda)^{2}} \\
&-\frac{v^{2} \lambda \times m \lambda(1-l)^{2}(1-x-y)^{2}}{4(c+I \lambda+m \lambda)^{2}} \\
& \pi_{2}^{K S}= \frac{4 \alpha(1-x-y)(1-l)(c+I \lambda+m \lambda)^{2}}{4(c+I \lambda+m \lambda)^{2}} \\
&+ \frac{v^{2} \lambda \times 2(c+I \lambda+m \lambda)(1-x-y)(1-l)[(1-l)(1-y)+l R]}{4(c+I \lambda+m \lambda)^{2}} \\
&-\frac{v^{2} \lambda \times\left[(c+I \lambda+m \lambda)(1-l)^{2}(1-x-y)^{2}-m \lambda(x(1-l)+l R)^{2}\right]}{4(c+I \lambda+m \lambda)^{2}} \\
& \pi=\pi_{1} \pi_{2}
\end{aligned}
$$

To obtain the Nash solution, we assume $\mathrm{d} \pi / \mathrm{d} x=0$, which is equal to 


$$
\begin{aligned}
& 16 \alpha^{2}(c+I \lambda+m \lambda)^{4}(1-l)[(1-l)(1-2 x-y)-l R]+4 \alpha v^{2} \lambda(c+I \lambda+m \lambda)^{2} \\
& \times(c+I \lambda+m \lambda)[x(1-l)+l R][(-2-x+2 y)(1-l)-3 l R]+4 \alpha v^{2} \lambda(c+I \lambda+m \lambda)^{2} \\
& \times(c+I \lambda+m \lambda)(1-l)(1-x-y))[(3-x-3 y)(1-l)+2 l R] \\
& +4 \alpha v^{2} \lambda(c+I \lambda+m \lambda)^{2} \times 3 m \lambda\left[(1-x-y)^{2}(1-l)^{2}-[x(1-l)+l R]^{2}\right] \\
& +\left(v^{2} \lambda\right)^{2}(1-l) \times[-2(c+I \lambda+2 m \lambda)[(1-l) x+l R] \\
& \times\left[(c+I \lambda+m \lambda)[x(1-l)+l R][(2-2 y-x)(1-l)+l R]-m \lambda(1-x-y)^{2}(1-l)^{2}\right] \\
& +\left(v^{2} \lambda\right)^{2}(1-l) \times(c+I \lambda+m \lambda)(1-x-y)(1-l)[(1-l)(1+x-y)+2 l R] \\
& \left.-\left(v^{2} \lambda\right)^{2}(1-l) \times m \lambda[x(1-l)+l R]^{2}\right] \times 2(c+I \lambda+2 m \lambda)(1-l)(1-x-y)=0
\end{aligned}
$$

That is $(1-l)(1-2 x-y)-l R=0$.

Therefore, the equilibrium revenue sharing is $x^{K S}=\frac{1-y}{2}-\frac{l R}{2(1-l)}$.

Proof of Proposition 4. Under pure revenue sharing, we can calculate the best level of firm improvement $\theta^{R S A}=\frac{\operatorname{vr} \lambda[I R+(1-l)(x+b y)]}{2(c+I \lambda)}$ if $\mathrm{d} \pi_{1}^{R S A} / \mathrm{d} \theta=0$.Then, substituting $\theta$ for the revenue functions, we obtain

$$
\begin{gathered}
\pi_{1}^{R S A}=\frac{4 \alpha(c+I \lambda)[l R+(1-l)(x+b y)]+v^{2} r^{2} \lambda[l R+(1-l)(x+b y)]^{2}}{4(c+I \lambda)} \\
\pi_{2}^{R S A}=\frac{(1-l)(1-x-y)}{2(c+I \lambda)} \times\left[2 \alpha(c+I \lambda)+v^{2} r^{2} \lambda[l R+(x+b y)(1-l)]\right] \\
\pi^{R S A}=\pi_{1} \pi_{2}
\end{gathered}
$$

In the same way, we calculate the Nash solution. If $\mathrm{d} \pi^{R S A} / \mathrm{d} x=0$,

$$
\begin{aligned}
& 8 \alpha^{2}(c+I \lambda)^{2}[(1-l)(1-2 x-y-b y)-l R] \\
& +2 \alpha(c+I \lambda) v^{2} \lambda[l R+(x+b y)(1-l)] \times 3[(1-l)(2-3 x-2 y-b y)-l R] \\
& +\left(v^{2} \lambda\right)^{2}[(x+b y)(1-l)+l R]^{2}[(1-l)(3-4 x-3 y-b y)-l R]=0
\end{aligned}
$$

As we know,

$$
\begin{aligned}
& {[(1-l)(1-2 x-y-b y)-l R]} \\
& <[(1-l)(2-3 x-2 y-b y)-l R]<[(1-l)(3-4 x-3 y-b y)-l R]
\end{aligned}
$$

therefore, if $[(1-l)(1-2 x-y-b y)-l R]>0, \quad x<\frac{1}{2}-\frac{l R}{2(1-l)}-\frac{(1+b) y}{2}$, the left side of the equation is greater than 0 , which means $\pi$ is increasing in $x$.

When $x>\frac{3}{4}-\frac{l R}{4(1-l)}-\frac{3 y+b y}{4},[(1-l)(3-4 x-3 y-b y)-l R]<0$, the left side of the equation is smaller than 0 . In addition, the second order derivative

$$
\begin{aligned}
\mathrm{d}^{2} \pi / \mathrm{d} x^{2}= & -8 \alpha^{2}(c+I \lambda)^{2} \times 2+2 \alpha v^{2} \lambda(c+I \lambda) \\
& \times 3[2(1-l)(1-3 x-y-2 b y)-4 l R] \\
& +\left(v^{2} \lambda\right)^{2}[(x+b y)(1-l)+l R] \times 2(1-l) \\
& \times 3[(1-l)(1-2 x-y-b y)-l R]<0
\end{aligned}
$$


Therefore, there is a solution that makes $\mathrm{d} \pi / \mathrm{d} x=0$. Therefore, we obtain the Nash solution that $\frac{1}{2}-\frac{l R}{2(1-l)}-\frac{(1+b) y}{2}<x^{R S A}<\frac{3}{4}-\frac{l R}{4(1-l)}-\frac{3 y+b y}{4}$. The proof is done.

Proof of Proposition 5. According to (19), we can calculate the best level of the firm improvement is $\theta=\frac{[(x+b y)(1-l)+l R] v \lambda}{2 k(c+I \lambda)}$. Put

$$
\begin{aligned}
& \theta=\frac{[(x+b y)(1-l)+l R] v \lambda}{2 k(c+I \lambda)} \text { into } \pi=\pi_{1} \pi_{2}, \text { we derive } \\
& \pi^{C S A}=\left\{16 k^{3}(c+I \lambda)^{2} \alpha^{2}[(1-2 x-y-b y)(1-l)-l R]+4 \alpha k(c+I \lambda)\right. \\
& \times 3 v^{2} \lambda[(x+b y)(1-l)+l R][2 k(1-x-y)(1-l)-[(x+b y)(1-l)+l R]] \\
&+2\left(v^{2} \lambda\right)^{2}[(1-l)(x+b y)+l R]^{2}[3 k(1-l)(1-x-y) \\
&-[(1-l)(x+b y)+b y](2-k)]\} /\left[16 k^{3}(c+I \lambda)^{2}\right]
\end{aligned}
$$

When $\partial \pi / \partial x=0, \partial \pi / \partial k=0$, we derive $x^{C S A}=\frac{1}{2}-\frac{l R}{2(1-l)}-\frac{y(1+b)}{2}$, $k^{C S A}=1 / 2$. Proposition 5 is proven.

Proof of Proposition 6. In the knowledge sharing mechanism, the new venture's quality improvements from the knowledge inputs of the incubator and the venture capitalist are $\theta_{1}^{K S A}=\frac{[(x+b y)(1-l)+l R] v \lambda}{2(c+I \lambda+m \lambda)}$ and $\theta_{2}^{K S A}=\frac{(1-x-y)(1-l) v \lambda}{2(c+I \lambda+m \lambda)}$, when the first-order conditions of $(22)$ and (23) are 0 .

$$
\pi=\pi_{1} \pi_{2}, \text { if } \mathrm{d} \pi / \mathrm{d} x=0,
$$

$16 \alpha^{2}(c+I \lambda+m \lambda)^{4}(1-l)[(1-l)(1-2 x-y-b y)-l R]$

$+4 \alpha v^{2} \lambda(c+I \lambda+m \lambda)^{3} \times[(x+b y)(1-l)+l R][(-2-x+2 y-3 b y)(1-l)-3 l R]$

$+4 \alpha v^{2} \lambda(c+I \lambda+m \lambda)^{3} \times(1-l)(1-x-y)[(3-x-3 y+2 b y)(1-l)+2 l R]$

$+4 \alpha v^{2} \lambda(c+I \lambda+m \lambda)^{2} \times 3 m \lambda\left[(1-x-y)^{2}(1-l)^{2}-[(x+b y)(1-l)+l R]^{2}\right]$

$+\left(v^{2} \lambda\right)^{2}(1-l) \times\{-2(c+I \lambda+2 m \lambda)[(1-l)(x+b y)+l R] \times[(c+I \lambda+m \lambda)$

$\left.\left.\times[(x+b y)(1-l)+l R][(2-2 y+b y-x)(1-l)+l R]-m \lambda(1-x-y)^{2}(1-l)^{2}\right]\right\}$

$+\left(v^{2} \lambda\right)^{2}(1-l) \times(c+I \lambda+m \lambda)(1-x-y)(1-l)[(1-l)(1+x-y+2 b y)+2 l R]$

$-\left(v^{2} \lambda\right)^{2}(1-l) \times 2 m \lambda[(x+b y)(1-l)+l R]^{2}(c+I \lambda+2 m \lambda)(1-l)(1-x-y)=0$

The formula can be simplified to $(1-l)(1-2 x)-l R=0$, and the solution is $x^{K S A}=\frac{1}{2}-\frac{l R}{2(1-l)}-\frac{y(1+b)}{2}$. The Proposition 6 is proven. 